\title{
Public Participation in Local Policy Decision-making: The Role of Web-based Mapping
}

\author{
Richard Kingston \\ Planning and Landscape, School of Environment and Development, University of Manchester, Oxford Road, \\ Manchester, Ml3 9PL, UK \\ E-mail: richard.p.kingston@manchester.ac.uk \\ Website: http://www.ppgis.manchester.ac.uk
}

New methods of using on-line interactive mapping are reported with a specific focus on how citizens can participate in the delivery and management of everyday services in their neighbourhood. Particular emphasis will be placed on how ICTs can be used to facilitate the regeneration of inner city neighbourhoods through more integrated approaches to spatial data management. The paper examines how internet mapping is used by the public through an interactive Public Participation GIS and illustrates how public access to on-line maps can help deliver improved services to local communities through the integration of GIS with a range of public services. This has raised some interesting issues in relation to how people understand mapping and their methods of navigation using such a system. With governments across the globe investing heavily in e-Government which includes on-line mapping facilities it is interesting to examine how the public actually perceive and use such systems.

\section{INTRODUCTION}

New methods of using on-line interactive mapping are reported here with a specific focus on how citizens can participate in the delivery and management of everyday services in their neighbourhood. The key to these new methods of delivering access to many public services are maps. Particular emphasis will be placed on how Information and Communication Technologies (ICTs) can be used to facilitate public engagement in the regeneration of inner city neighbourhoods through more integrated approaches to spatial data management. The paper will discuss how mapping is used by the public through an interactive Public Participation GIS (PPGIS) to report problems in local neighbourhoods. While it is recognised that traditional paper maps have many virtues they can become even more powerful decision and policy supporting tools when used as part of a GIS. Indeed, it has been possible for around a decade now to gain access to online GIS which allow users to 'create and modify them to meet specific and individual needs' (Wood, 2003, p. 111).

In this paper, the concepts of active citizenship and public participation in neighbourhood regeneration are examined with a specific focus on the role of spatial technologies. To achieve this, a case study is carried out in a large metropolitan city in the UK, where the role of new ICTs is examined in relation to the regeneration of an urban neighbourhood, the eastern area of the City of Manchester. Then, some of the specific tools which have been developed and tested alongside current regeneration processes are examined. To conclude, an assessment is made of how ICTs and egovernance practice can support the provision of better urban planning and management services.

\section{ACTIVE CITIZENSHIP IN NEIGHBOURHOOD REGENERATION: THE ROLE OF WEB-BASED MAPPING}

A key focus of all European governments is how to manage and sustain the economic and environmental assets of local communities. Within a UK context, a plethora of government policies focused on neighbourhood renewal (Cabinet Office, 2001) have at the centre of them the concept of active citizenship. It can be argued that the roots of active citizenship lie with the political and professional elite (Kearns, 1995) but more recently the concept has shifted to meaning the engagement of people from all walks of life in deciding how their local community or neighbourhood should be managed and planned. Indeed recent research by the Joseph Rowntree Foundation found that active citizen engagement is likely to improve the effectiveness of neighbourhood regeneration projects both in building personal and community capacity, and in achieving tangible regeneration outcomes, particularly in deprived neighbourhoods (Beresford and Hoban, 2005). 
The overall objective of active citizenship is to enable people to achieve a multitude of benefits by becoming more actively engaged in their communities with the aim of improving local services and the fabric of their area. This has ranged from citizen panels and local area panels (ODPM, 1998) to very interactive methods such as Planning for Real ${ }^{\circledR}$ (NIF, 2006) which makes use of physical models to glean ideas from the community about the re-development of their neighbourhood. More recently, there has been a move to making more use of new ICT through the Internet and digital TV (Kingston et al., 2000 and Kingston, 2002) to complement these more traditional methods. In an attempt to test the usefulness of these new approaches to participation recent research in the City of Manchester has been piloting a range of web based mapping tools allowing the public to engage in neighbourhood regeneration.

The purpose of these tools is to provide tangible means to help planners, policy makers and citizens of varying backgrounds build consensus about the design and development of a place. If used properly these tools are meant to help people make better planning decisions by enabling improved communication, design and analysis (AlKodmany, 2002, Craig et al., 2002, Hudson-Smith et al., 2002 and Kingston et al., 2000) in place making and central to these tools is the digital map. One of the aims of this research has been to enable more active participation in the decision making process through the exploitation of web-based mapping systems. Work by the OECD (2001) examined the types of public involvement in government decision-making which they defined as follows:

1. Information and transaction - government informs citizens (one way process)

2. Consultation - government consults with citizens (citizen's responses generally predetermined by government via multiple-choice, closed-question options)

3. Deliberative involvement - government engages citizens in consultation process (citizens encouraged to deliberate over issues before final response)

4. Government-led active participation - government instigates consultation and retains decision-making powers

5. Citizen-led active participation - citizens are actively engaged in decision-making processes, alongside government; citizen decisions become binding; citizens share ownership and responsibility over outcomes.

In far too many cases, citizens' interaction with public bodies tends to be focused on types 1 and 2 above. With web-based mapping, the potential exists to move interaction into types 3,4 and 5 . A further aim of the research has been to provide the necessary tools, skills, knowledge and understanding to allow citizens to fully engage in the regeneration process through types $3 \mathbf{- 5}$. One of the keys to this engagement is interactive web-based mapping.

\section{WEB BASED MAPPING AND E-PARTICIPATION}

Over recent years, traditional methods of participation have been criticised by many (Healey, 1998) for several reasons.
The primary methods of participation are nearly always held in a fixed place or location and at a fixed time, often when people are at work or in the evening when other commitments mean people cannot attend meetings, etc. The meetings are quite often confrontational, they can be dominated by vocal minority groups, it is often difficult for the layperson to understand, and the whole process quite often involves highly technical and legal 'jargon'. Over recent years, the author has been investigating alternative methods of participation in planning and regeneration by making use of ICTs and web-based PPGIS with the map being the key focus and gateway into participation in the planning system. In the mid 1990s, a number of examples were developed which made use of GIS technology within public participation.

Methods developed by Shiffer (1995) provided the public with access to multi-media planning tools and computer-supported collaborative working environments within a PC-based collaborative planning system. Shiffer concluded that increased access to relevant information, aided by the implementation of a collaborative planning system led to greater communication among participants in a group planning situation, which, in due course, had a positive effect on the quality of plans and decisions made by the planning authority. Using Shiffer's stand-alone systems research by the author and colleagues led to the development of web-based participatory mapping tools. Various PPGIS developed over recent years (Craig et al., 2002; Hudson-Smith et al., 2002 and Kingston et al., 2000) have mirrored traditional planning process to ascertain whether or not such systems have a role to play within the planning system. This has been complimented over the same time period by the British Government's commitment to the eGovernment agenda. A key focus of the systems which have been developed has been on giving the public a greater degree of engagement in planning issues and access to the relevant tools, data and information to enable more informed participation and decision making. For example, most planning documents tend to be fairly lengthy and cumbersome often containing some form of policy proposals map as an insert at the end of the document in an attempt to visualise proposed spatial policies. For most people wishing to engage in the planning system they want to know which policies affect where they live and work. Therefore, a more appropriate method of examining which policies affect them may be to focus on the map and pull out relevant policies at a particular location. By providing access to on-line interactive planning documents, the public can interrogate policies at particular locations rather than wade through a lengthy document to find policies which may have implications for particular locations. This is not something to underestimate as many of these types of documents can be several hundred pages long.

For some time now GIS have been used by the public sector for the management of housing stock, infrastructure and the analysis of social and economic variables, but have been criticised as an elitist technology in the past (Pickles, 1995). In a major review of technology for urban eGovernance, researchers found that 'Several cities provide fully functional GIS. Visitors to these sites can obtain a variety of information, depending on the site. Some allow 
address look-up. Others provide maps of proposed city projects. Several cities offer slightly less functional GIS or as-built GIS images that are available for download.' (Christodoulou et al., 2004, p. 27). While this can be seen as a useful function in itself it does not provide the kinds of interaction that are possible within a public-facing GIS. Traditionally, GIS has been a technology which has run on large computer systems, then migrating to desktops and, more recently, the software has been able to work across the Internet. This has provided many opportunities to provide access to data previously unavailable to the public.

\section{THE MANCHESTER CASE}

The City of Manchester has a long history of championing urban regeneration projects and is well placed for using parts of the City for the development and testing of new techniques in urban regeneration. With this in mind, a large area of the city known as New East Manchester (NEM, 2006) has been used to implement new e-participation tools developed as part of IntelCities ${ }^{1}$. Over recent years since NEM was set up, the area has seen considerable inward investment to help regenerate the community after decades of decline. From the perspective of the research, there have been a number of significant factors in the Manchester experience of using IT in managing urban change. There has been a strong tradition of supporting the use of ICT in business and community development. This goes back over 15 years with the launch of the Manchester Host - the UK's first-ever public-access integrated email; the creation of a bulletin board and online database service in 1991, through to the development of the Electronic Village Halls in 1992 (Harvey et al., 2002), the Manchester Community Information Network in 1994 and the Manchester Digital Development Agency (MDDA) in 2003.

The underpinning philosophy of these initiatives has been that technology is a means to achieve sustainable regeneration rather then allowing the technology to dominate the regeneration process. Through a range of projects such as the network of Internet access centres in libraries across the city and the largest network of UK Online for Learning and Learn Direct Centres in the UK, there has historically been greater than average access to ICT by citizens in Manchester. NEM has also been successful in securing considerable funding from the UK government and through European Regional Development Funds which has helped to support a local wireless network covering an area of 9000 households. Approximately 3500 PCs were purchased by residents at a subsidised rate and there are currently over 1250 users on the network equating to a much higher rate of Internet usage than the UK on average. The community website (http:// www.eastserve.com) developed by a local partnership of statutory and voluntary organisations led by the City Council is seen as an important part of the regeneration process. It has been used as one of the vehicles for public engagement and testing the usability of the technology developed as part of IntelCities. There are still many recognised problems associated with social access to the internet (Liff et al., 2002) and its associated technologies and these should not be overlooked. The research undertaken as part of IntelCities has been attempting to look at the future of cities in the information age and has therefore paid less attention to social access issues.

As many cities have started to take on board the eGovernment agenda they have investigated which services can be e-enabled. In Manchester's case, one example is the Council's Environmental Services which allow citizens to report environmental problems through a part of their web site called Environment on Call (EoC). People can report problems in relation to a range of environmental and social issues via telephone, textphone, text messaging, e-mail and on-line forms. Staff are on hand to take telephone enquiries Monday to Friday from 8 am to $8 \mathrm{pm}$. For example, you can report a problem with grounds maintenance, such as parks or gardens, or road and pavement problems. You are required to describe the problem and be as specific as possible with regards to its location. It is also necessary to leave contact details. In many cases, EoC staff are required to telephone the person making the inquiry to clarify the exact location of the problem. Once an enquiry is received, a call centre operative uses an in-house GIS and attempts to identify the exact location on a map based on instructions received from the complainant which can be a fairly time consuming task. This process is outlined in Figure 1. Once the location has been identified the call centre operative produces a report which is then forwarded to the relevant team on the ground to deal with the problem. This involves a pro-forma with the necessary details on a map produced from the in-house GIS. It can often take several days to deal with a problem, particularly if a specific council service has not been e-enabled and must therefore use internal mail or a fax to pass on the details of the problem.

A major part of e-Government is to enhance and better manage services that cities deliver to citizens. In the next section, it is shown how the EoC system has been streamlined to improve the way in which citizens report problems using a web-based mapping interface. This allows citizens to pinpoint the exact location of a problem they wish to report on a map rather than explaining this verbally or in written form. This has raised some interesting issues in relation to how people understand mapping and their methods of navigation. As part of this research, the EoC system has been re-designed as a spatially enabled environmental reporting system as outlined in Figure 2. The addition of a GIS interface, highlighted in Figure 3, into the EoC service has allowed citizens to identify the exact location on the map themselves, select the service domain (e.g. abandoned car or uncollected refuse) and fill in the necessary details such as the make of model of the vehicle and its colour. One of the advantages of this type of system is that the enquiry goes directly to the relevant team who deal with the specific service, rather than through the call centre, providing a report of the problem and a map electronically. In some circumstances, it is expected that the system will be further developed in the future to be transmitted directly into a vehicle using GPS for example when domestic refuse is not collected or dealing with an abandoned vehicle. With regards to reporting criminal activity, it is possible for the report to go directly to a police 


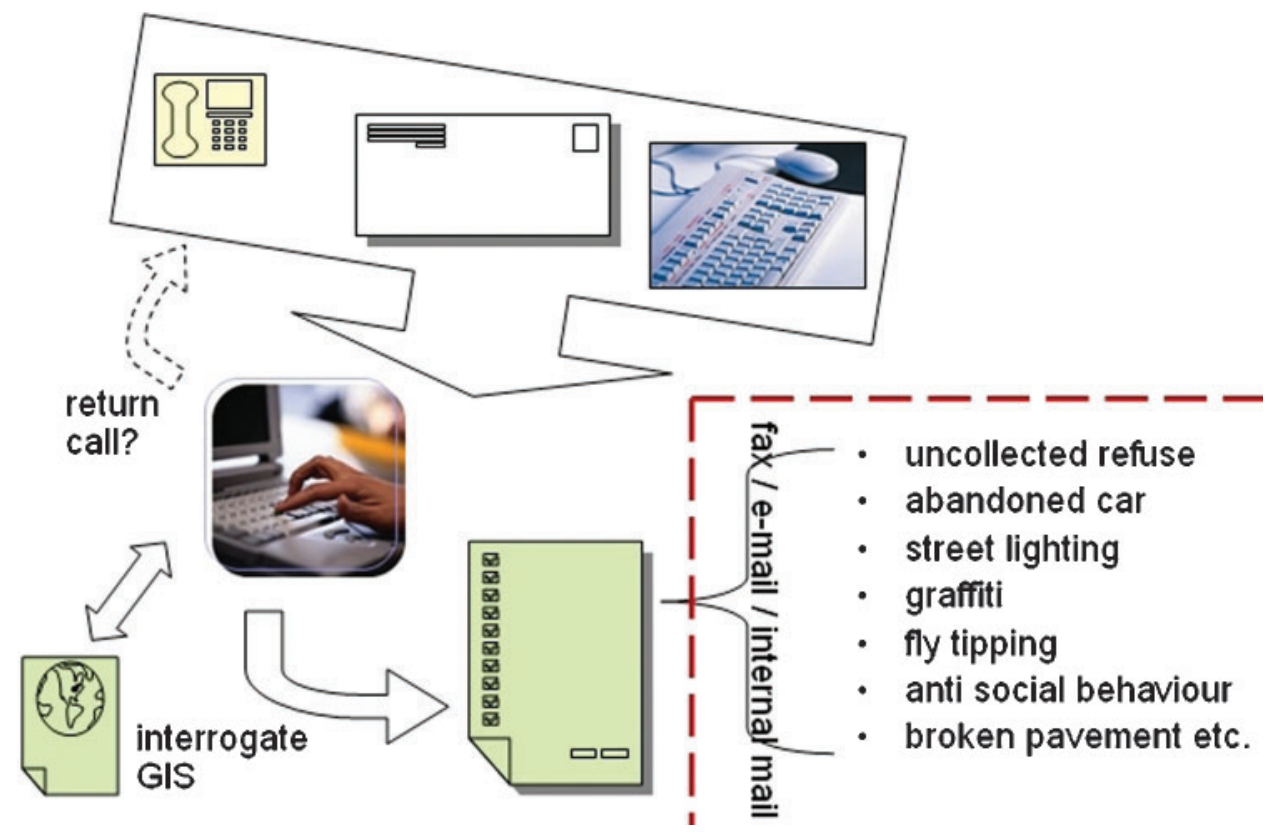

Figure 1. Current process for dealing with environmental reporting

officer patrolling the area concerned via SMS. As well as providing a more streamlined service between citizen and street operative, the system also provides new intelligence on service delivery and management. The system generates a geo-referenced database which allows policy makers to monitor the types of complaints and enquiries being reported. This allows the city council to map and monitor the spatial location of the different types of service enquiry in real time allowing them to investigate persistent problems and target resources to appropriate parts of the city.

Some may be critical of using mapping interfaces to access public services for use by the general public due to issues relating to map literacy. Having tested PPGIS for nearly 10 years in local, regional and national decision making environments evidence from a range of studies would suggest that many people are quite adept at navigating around such an on-line interface. By providing a facility to search for a street name or postcode and then have the map zoom to that location previous user testing (Kingston et al., 2000) has found that users can quickly identify their street and indeed their house and then navigate to other locations by following a known route along a street. The provision of points on the map with linked digital photographs and panoramic views of well known landmarks also helps users orientate themselves on the map. Testing of these systems with members of the public also found that younger people would often navigate around the interface and parents and older relatives would then inform them of what to comment about (ibid).

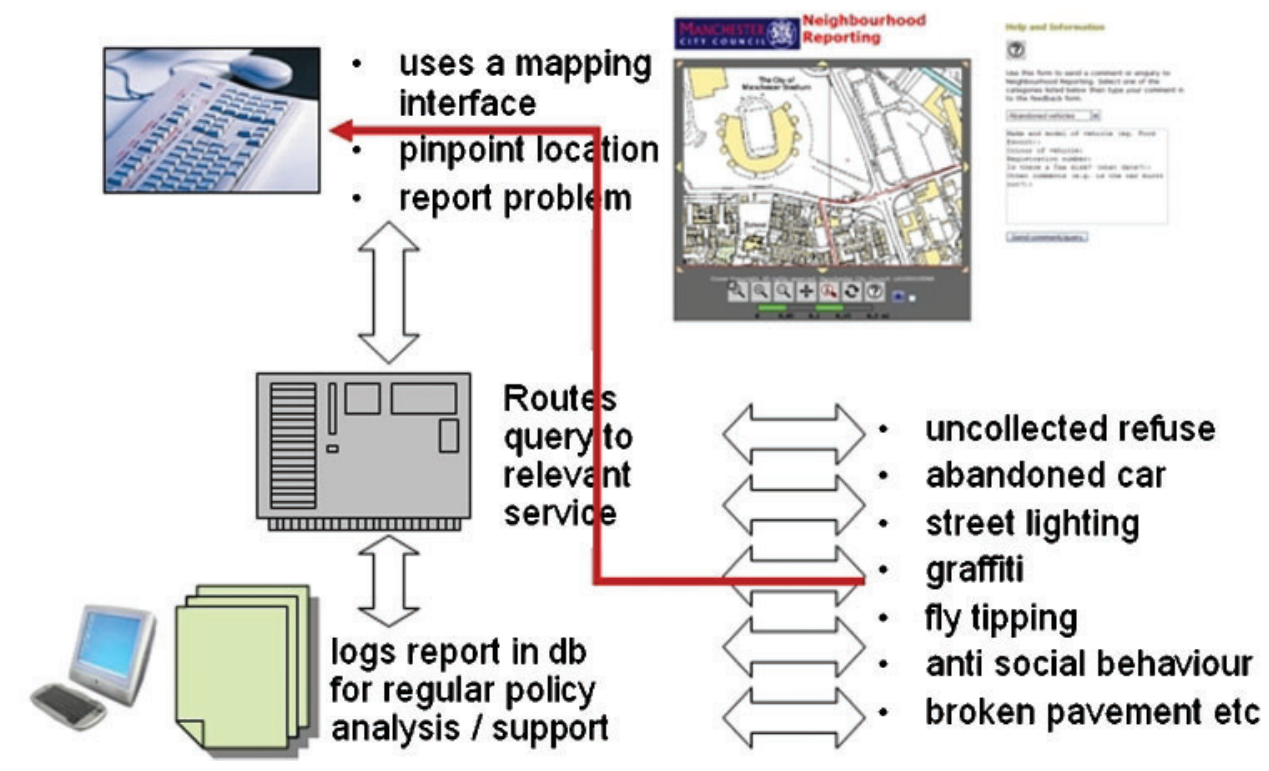

Figure 2. Web-based map enabled method for environmental reporting 


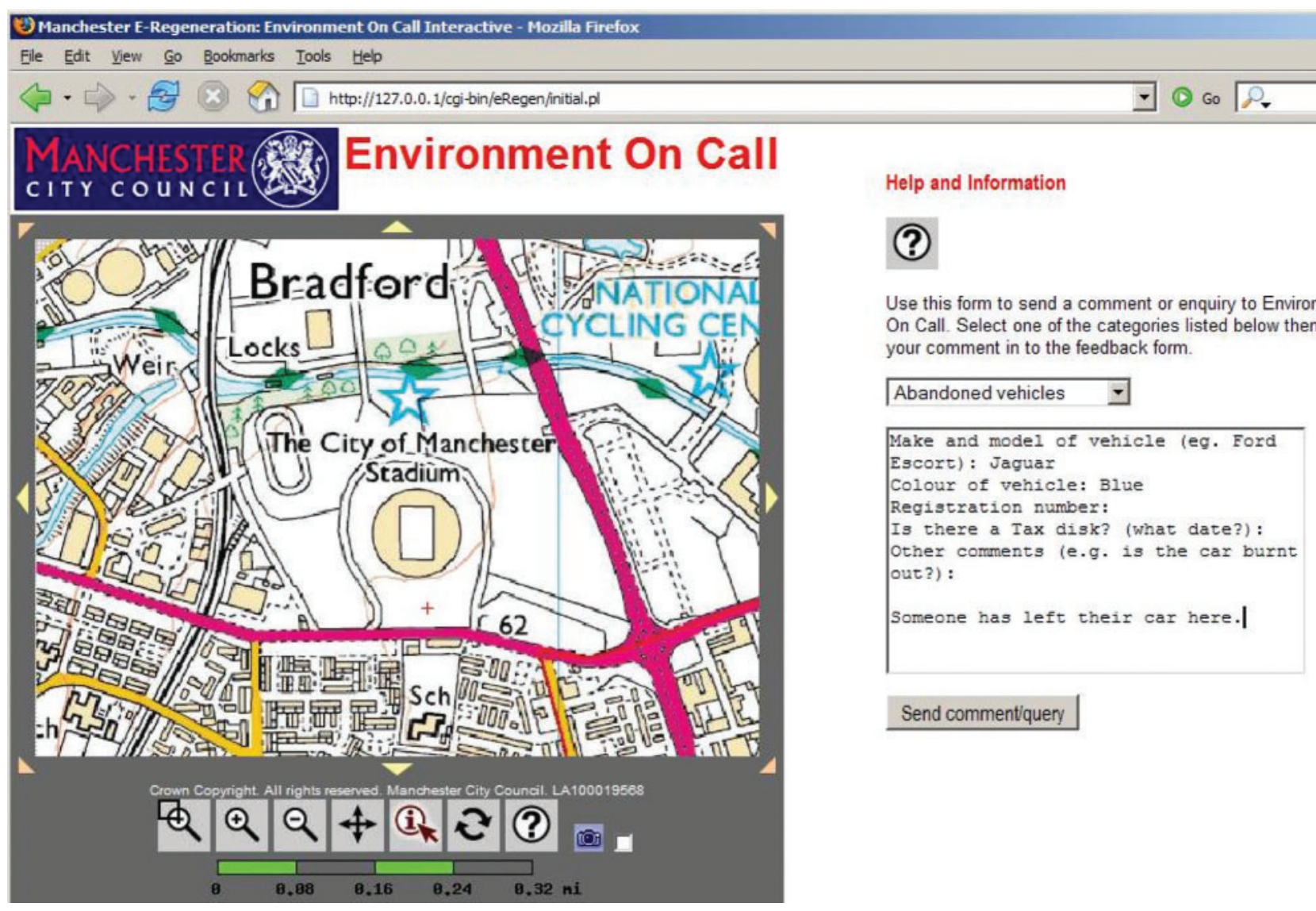

Figure 3. The mapping interface

\section{MAP FUNCTIONALITY}

The EoC system developed as a part of IntelCities is based on the Open Geospatial Consortium compliant Web Map Server (WMS) technology and supports a range of spatial data formats including ESRI Shape files, MapInfo and various raster data formats such as geoTIFF. It also has functions for the inclusion of further geospatial layers to show relevant spatial policy data and information, etc. It makes use of CGI executable files for the processing and management of user comments and feedback using the PHP scripting language. Users can navigate the map by zooming and panning into an appropriate location and turning relevant map layers on or off and querying these layers for relevant attribute information. There is also a function called 'zoom to box' that allows the user to draw a rectangle using the mouse. There is also the option of searching for a location by street name or postcode. A postal address/coordinate look-up table to identify $x, y$ co-ordinates against postal address is stored on the web server. This is used by the application to support the address search functionality and to enable co-ordinates to be passed to the WMS so it can display a map zoomed in to the desired map image.

The type of mapping displayed is determined by the scale at which the user is viewing the map. Initially, the user sees 1:50 000 OS Landranger and the map becomes more detailed as they zoom in with 1:10 000 OS Landplan data being the most detailed. The scaling details are outlined in Table 1.
The focus of the system described above is on reporting problems or making enquiries and not necessarily about consultation and participation. Further research in addition to EoC has been developing an e-Participation system aimed at supporting and improving open and transparent dialogue which has a spatial planning and regeneration focus. Using the same mapping interface the system allows citizens to discuss new proposals or identify issues relating to space and place regeneration within their community. Users start discussions and debate issues and thereby, in a sense, create their own geo-referenced community database. Users can navigate the map by zooming and panning into an appropriate location and turning relevant map layers on or off in relation to spatial policies and querying these layers for relevant attribute information. A new discussion can be started by switching to the appropriate mode and clicking on an appropriate location and initiating a discussion on a new or predefined topic. Other users can search the map for discussions based on a specific topic, keyword or click

Table 1. Map types and scale

\begin{tabular}{llll}
\hline Scale & Map type & Data type & Scale range \\
\hline $1: 10000$ & OS Landplan & Colour raster & $500-5000$ \\
$1: 25000$ & OS Explorer & Colour raster & $5000-10000$ \\
$1: 50000$ & OS Landranger & Colour raster & $10000-100000$ \\
\hline
\end{tabular}


on point locations on the map to view previous discussion and make appropriate comments themselves. In relation to the OECD's (2001) typology of public involvement referred to earlier the e-Participation system can fulfil task 5 to assist citizen-led participation in the regeneration decision-making process.

\section{E-PARTICIPATION AND THE PROVISION OF BETTER SERVICES}

Before developing the map-enabled system the city council would spend a lot of time attempting to identify the location of a problem which a member of the public was reporting. Using the mapping interface, the EoC database stores geo-referenced complaints and enquiries based on the type of complaint made. This allows policy officers to monitor in a GIS the spatial dispersion across the city of service use. They can monitor in real time whether there is clustering of particular problems and target resources appropriately as and when problems occur. For example, if a cluster of missed bins or vandalised cars are appearing in a particular part of the city they can investigate why this is occurring at particular locations and take the necessary actions to alleviate any problems. Many may still be unconvinced of the relevance of using map-based interfaces for this type of application but, since undertaking this research, the UK government has funded a national pilot project (mySociety, 2007) that works along similar lines to the system reported here. This UK national website allows the input of a postcode or place name which then zooms to a map and allows a comment to be made similar to EoC.

The European Commission's i2010 Communication notes that making public services better, more accessible and more cost-effective is a key challenge. In spite of considerable advances achieved in the rollout of electronic public services 'much remains to be done to demonstrate economic impact and social acceptance of e-government'. (European Commission, 2005). This research has started to address these e-government aspirations specifically on the issue of public involvement in planning and regeneration. IntelCities visibly supports the EU's Action Plan on eGovernment for citizen-centred services by enabling citizens to play a far more participative and inclusive role in city planning via spatially enabled e-Participation systems. The development of the e-Participation systems outlined above and the provision of these services in NEM is a visible step in addressing the goals of improved eGovernment. The systems developed here are focused on NEM, they are scalable and can be expanded to include the whole of the Manchester Metropolitan district and the wider city-region. Indeed, the system can work in any place by changing the spatial data to the appropriate location. All the systems discussed here have been developed using Open Source software and meet e-Government interoperability framework requirements. In terms of the future development of such systems, work is underway looking at the user interface design to see if the public prefer aerial photography rather than maps among other issues. Further development also includes moving from 2-D GIS mapping to more immersive 3-D virtual worlds exploiting developments such as Google Earth.

A key issue for the public when using such systems relates to trust and confidence in the systems being used. Trust is essential for on-line participation to work successfully, and by successfully we mean getting a good response and for the system not to backfire badly. There are two essential ingredients to public trust in such systems: trust that something will be done and the system not abused, and trust in the information given and the process. If you lose either of these you will not simply have failed, you will have done positive harm to the planning process. Workshops undertaken with citizens in NEM highlighted the fact that we can design the most userfriendly system in the world but if the comments and complaints made through the system are not quickly acted upon we may as well not bother. A concern of citizens has been that such systems will not change what happens on the ground as it is still the same organisation and people making decisions whether you complain by letter, telephone, in person or by e-mail.

While EoC is limited in its ability to improve government decision-making and focus more on increasing government efficiency, the e-Participation system is capable of increasing the level of access citizens have to the decision-making process - so long as the politicians listen to what the community is telling them and act upon it. As well as improving the types of services offered to citizens it also provides opportunities for improving the management of cities and helping achieve long term physical, social and economic sustainability. These systems are still in the early stages of development and testing and there are many issues still to be resolved. These include whether a moderator should be present to control and direct discussions and make sure they keep to the main regeneration or planning issues of the day. If such a person is present should they be a representative of the local government, an independent community organisation or local politicians? Which mapping layers should or should not be included and who decides what spatial data is most appropriate? Further testing is also envisaged to examine the benefits of using aerial photos and whether citizens should be able to add their own material such as photos, other graphics and mapped data to the system. For example should users be able to upload their own spatial data rather than just comment on what is provided in ways similar to OpenStreetMap (http://wiki.openstreetmap. org).

One of the key factors to the success of delivering services in this way is a clear, well presented and understandable interactive map. Key questions still remain unanswered though. While we can develop, test and implement webbased mapping systems, there is still little evidence available as to how much the public are using such systems. With vast amounts of money invested in e-Government there is a reluctance by local and national government to divulge data on access and usage and one suspects that current usage of e-channels is relatively low compared with more traditional methods. What is certain though is that e-Government is here to stay and is backed up by international governmental policy across the globe. 


\section{NOTES}

i IntelCities is an EU Information Society Technologies $6^{\text {th }}$ Framework Project. Its main aim is to help achieve the EU policy goal of the Knowledge Society by 2010 through new forms of electronic governance of cities and greater social inclusion through enhanced access to services by citizens and businesses. See http://www. intelcitiesproject.com for further details.

\section{BIOGRAPHICAL NOTES}

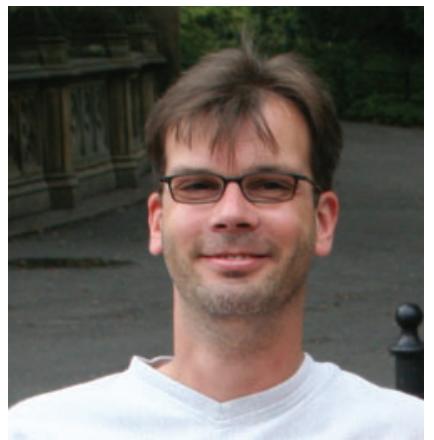

Richard Kingston is a lecturer in urban planning and GIS at the University of Manchester in the UK. Over the past 10 years he has been undertaking research investigating the use of ICT in urban and regional planning, focusing on the development of Public Participation Geographical Information System methods and softRichard Kingston ware tools to enhance the more traditional participa-

tory processes within planning.

\section{ACKNOWLEDGEMENTS}

An earlier version of this paper was presented at the British Cartographic Society Annual Technical Symposium in Manchester, September 7-10, 2006. Parts of this research were funded by the EU FP6 IST IntelCities project No. 507860.

\section{REFERENCES}

Al-Kodmany, K. (2002). 'GIS and the Artist: Shaping the Image of a Neighbourhood in Participatory Environmental Design'. In: Craig, W., Harris, T. and Weiner, D. (ed.) Community Empowerment, Public Participation and Geographic Information Science. London: Taylor \& Francis.

Beresford, P. and Hoban, M. (2005). 'Participation in Anti-poverty and Regeneration Work and Research: Overcoming Barriers and Creating Opportunities'. York: Joseph Rowntree Foundation.

Cabinet Office (2001). A New Commitment to Neighbourhood Renewal: National Strategy Action Plan. London: Social Exclusion Unit.
Christodoulou, E., Samaras, G. and Germanakos, P. (2004). 'Technologies for Urban eGovernance Currently in Use: Review and Classification'. IntelCities WPII Deliverable 3.2. http://www.intelcitiesproject.com, accessed 12 December 2006.

Craig, W., Harris, T. and Weiner, D. (eds.) (2002). Community Empowerment, Public Participation and Geographic Information Science. London: Taylor \& Francis.

European Commission (2005). 'European Commission Unveils New Information Society Strategy', Press release 2 June http:// europa.eu.int/idabc/en/document/4340, accessed 12 December 2006

Harvey, P. M., Green, S. and Agar, J. (2002). 'From Cotton to Computers: the Social Contexts of Virtual Manchester'. In Woolgar, S. (ed) Virtual Society. Oxford: Oxford University Press.

Healey, P. (1997). Collaborative Planning - shaping places in fragmented societies. London: Macmillan.

Healey, P. (1998). 'Building Institutional Capacity Through Collaborative Approaches to Urban Planning. Environment and Planning A, 30, 1531-1546.

Hudson-Smith, A., Evans, S., Batty, M. and Batty, S. (2002). 'Online Participation: The Woodbury Down Experiment'. CASA Working Paper No. 60. London: CASA, UCL.

Kearns, A. (1995). 'Active Citizenship and Local Governance: Political and Geographical Dimensions'. Political Geography, 14(2), 155175.

Kingston, R. (2002). 'Web Based PPGIS in the UK'. In: W. Craig (ed.) Community Empowerment, Public Participation and Geographic Information Science. London: Taylor \& Francis.

Kingston, R., Carver, S., Evans, A. and Turton, I. (2000). 'Web-Based Public Participation Geographical Information Systems: An Aid To Local Environmental Decision-Making'. Computers, Environment and Urban Systems. 24(2) 109-125.

Liff S. T., Steward, F. and Watts, P. (2002). 'New Public Places for Internet Access - networks for practice based learning and social inclusion.' In: Woolgar, S (ed.) Virtual Society? Technology, cyberbole, reality, Oxford: Oxford University Press.

mySociety (2007). 'Neighbourhood Fix-It' http://www.neighbourhoodfixit.com, accessed 8 March 2007.

NEM (2006). 'Sustainable Regeneration in East Manchester' http:// www.neweastmanchester.com, accessed 12 December 2006.

NIF (2006). 'What is Planning for Real?' http://www.nif.co.uk, accessed 12 December 2006

ODPM (1998). Guidance on Enhancing Public Participation in Local Government. London: Office of the Deputy Prime Minister.

ODPM (2004). Market Renewal Pathfinders: Learning Lessons. London: Office of the Deputy Prime Minister.

OECD (2001). Citizens as Partners: Information, Consultation and Public Participation in Policy-making. Paris, OECD.

Pickles, J. (ed.) (1995). Ground Truth. The Social Implications of Geographic Information Systems, New York, Guilford Press.

Shiffer, M. (1995). 'Interactive Multimedia Planning Support: Moving from Stand Alone Systems to the World Wide Web'. Environment and Planning B: Planning and Design, 22, 649-664.

UNECE (1998). Convention on Access to Information, Public Participation in Decision-making and Access to Justice in Environmental Matters. Geneva, UNECE.

Wood, M. (2003). 'Some Personal Reflections on Change... The Past and Future of Cartography', The Cartographic Journal 40(2) $111-115$. 